\title{
Effect of Recombinant Human Tumor Necrosis Factor-alpha on Cerebral Oxygen Uptake, Cerebrospinal Fluid Lactate, and Cerebral Blood Flow in the Rabbit: Role of Nitric Oxide
}

\author{
Jay Tureen \\ Department of Pediatrics, University of California San Francisco, San Francisco, California 94143
}

\begin{abstract}
Among the important pathophysiologic alterations in the brain in bacterial meningitis are abnormalities of cerebral circulation and metabolism; however, the precise mechanisms by which these disturbances occur are not completely delineated. It has been recently recognized that cytokines are produced by tissues in the central nervous system in meningitis and play a critical role in the host inflammatory response. Because these mediators are involved in circulatory and metabolic disturbances in other tissues in sepsis, we investigated the role of tumor necrosis factor-alpha in the central nervous system in a rabbit model. We found that injection of recombinant human TNF into the cisterna magna in the rabbit led to an acute reduction in cerebral oxygen uptake and a more prolonged reduction in cerebral blood flow. This was accompanied by an increase in intracranial pressure and an increase in cerebrospinal fluid lactate. Reduction in oxygen uptake and increases in intracranial pressure and CSF lactate were blocked by pretreatment with L-NAME, an inhibitor of nitric oxide synthase. Reduction in cerebral blood flow was not affected by L-NAME treatment and was due to increased cerebrovascular resistance and reduced oxygen demand. These results suggest that TNF may be a critical mediator of changes in cerebral circulation and metabolism and that some of these changes occur via the nitric oxide pathway. (J. Clin. Invest. 1995. 95:1086-1091.) Key words: tumor necrosis factor • nitric oxide $\cdot$ cerebral blood flow $\cdot$ cerebral metabolism $\cdot$ meningitis
\end{abstract}

\section{Introduction}

The mechanisms of brain injury in bacterial meningitis are incompletely delineated. Clinical studies have demonstrated that poor neurologic outcome is associated with factors related to

Address correspondence to Jay Tureen, M.D., University of California San Francisco, 505 Parnassus Ave., Box 0811, San Francisco, CA 94143-0811. Phone: 415-206-3797; FAX: 415-206-6015.

Received for publication 13 May 1994 and in revised form 27 October 1994.

1. Abbreviations used in this paper: $\mathrm{CBF}$, cerebral blood flow; CNS, central nervous system; $\mathrm{CP}$, choroid plexus; CSF, cerebrospinal fluid; ICP, intracranial pressure; NOS, nitric oxide synthase.

J. Clin. Invest.

(c) The American Society for Clinical Investigation, Inc.

0021-9738/95/03/1086/06 \$2.00

Volume 95, March 1995, 1086-1091 both the host and to the infecting organism. Studies in experimental models of meningitis have delineated a cascade of events within the central nervous system (CNS), ${ }^{1}$ wherein lysis of bacteria in the subarachnoid space (SAS) stimulates release of cytokines which is then followed by increased concentration of white blood cells in cerebrospinal fluid (CSF) (1). While the inflammatory response to cytokines in meningitis has been well characterized, the potential circulatory and metabolic effects of cytokines on the brain have not been thoroughly investigated.

It has been recognized for some time that lactate is increased in CSF in bacterial meningitis, suggesting enhanced anaerobic metabolism within the CNS (2-4). The source of CSF lactate has been variously ascribed to production by bacteria and white blood cells in the SAS (5); however, we have demonstrated by in vivo microdialysis that there is increased brain tissue concentration of lactate in meningitis (6). We have also shown that the mechanism of increased lactate production by the brain in meningitis is, in part, mediated by cerebral ischemia; however, increased CSF lactate is present even with normal levels of cerebral blood flow (7), raising the possibility that other mechanisms exist. We have recently demonstrated in experimental pneumococcal meningitis in the rabbit that cerebral blood flow and cerebral oxygen uptake are inversely correlated and that CSF lactate concentration is directly correlated with CSF TNF- $\alpha$ concentration, suggesting that TNF may have metabolic effects on the brain similar to those seen in peripheral tissues, where it is thought to be an important mediator of the metabolic consequences of sepsis, with some of the effects occurring as a result of generation of nitric oxide. The purpose of the present study is to determine whether TNF has a direct effect on cerebral cellular metabolism and cerebral blood flow, and to identify whether these effects could be mediated by activation of the nitric oxide pathway.

\section{Methods}

New Zealand white rabbits $(2.0-2.5 \mathrm{~kg})$ of both sexes were used. Rabbits were fed a standard diet and were housed in accordance with the guidelines of the Committee on Care and Use of Laboratory Animal Resources, the National Research Council. All studies were reviewed and approved by the Animal Research Committee of the University of California San Francisco. On the morning of the studies, rabbits were anesthetized with intravenous urethane (Fluka Chemie AG, Buchs, Switzerland) $2.0 \mathrm{gm} / \mathrm{kg}$. A peripheral intravenous line, right carotid artery line, and femoral artery line were placed as previously described (8). A 22-gauge intravenous cannula was placed in the sagittal sinus through a 4-5-mm burr hole in the cranium which was then sealed with cyanoacrylate cement and dental acrylic. Anesthetized animals were secured in restraining frames containing a geared micromanipulator which holds a spinal needle, permitting direct puncture of the cisterna magna for injection and CSF sampling. Arterial and venous blood gas measurements were made in a portable blood gas laboratory (ABL2; Radiometer, 
Table I. Arterial Blood Gases

\begin{tabular}{|c|c|c|c|c|}
\hline & $0 \mathrm{~h}$ & $2 \mathrm{~h}$ & $4 \mathrm{~h}$ & $6 \mathrm{~h}$ \\
\hline \multicolumn{5}{|l|}{$\mathrm{pH}$} \\
\hline Control (8) & $7.32 \pm 0.04$ & $7.31 \pm 0.06$ & $7.31 \pm 0.05$ & $7.32 \pm 0.05$ \\
\hline rhuTNF (8) & $7.30 \pm 0.02$ & $7.35 \pm 0.03$ & $7.32 \pm 0.03$ & $7.37 \pm 0.05$ \\
\hline $\begin{array}{l}\text { rhuTNF + } \\
\text { L-NAME (6) }\end{array}$ & $7.33 \pm 0.04$ & $7.33 \pm 0.02$ & $7.36 \pm 0.04$ & $7.36 \pm 0.05$ \\
\hline \multicolumn{5}{|l|}{$\mathrm{p}_{\mathrm{a}} \mathrm{O}_{2}(\mathrm{~mm} \mathrm{Hg})$} \\
\hline Control & $76.2 \pm 16.7$ & $75.6 \pm 18.8$ & $76.0 \pm 18.1$ & $72.8 \pm 17.7$ \\
\hline rhuTNF & $87.1 \pm 14.8$ & $89.3 \pm 13.0$ & $85.0 \pm 15.8$ & $87.1 \pm 12.1$ \\
\hline $\begin{array}{c}\text { rhuTNF + } \\
\text { L-NAME }\end{array}$ & $85.6 \pm 6.5$ & $86.0 \pm 11.1$ & $92.6 \pm 14.1$ & $93.6 \pm 11.6$ \\
\hline \multicolumn{5}{|l|}{$\mathrm{p}_{\mathrm{a}} \mathrm{CO}_{2}(\mathrm{~mm} \mathrm{Hg})$} \\
\hline Control & $40.2 \pm 6.9$ & $40.1 \pm 7.5$ & $38.7 \pm 3.3$ & $36.6 \pm 3.7$ \\
\hline rhuTNF & $39.0 \pm 3.4$ & $37.1 \pm 6.6$ & $37.6 \pm 8.1$ & $33.6 \pm 6.1$ \\
\hline $\begin{array}{l}\text { rhuTNF + } \\
\text { L-NAME }\end{array}$ & $39.5 \pm 2.6$ & $33.7 \pm 3.2$ & $30.0 \pm 4.1^{\ddagger 8}$ & $29.0 \pm 5.7 *$ \\
\hline \multicolumn{5}{|l|}{ Base excess } \\
\hline Control & $-6.6 \pm 2.5$ & $-6.7 \pm 2.5$ & $-8.1 \pm 2.0$ & $-6.6 \pm 3.9$ \\
\hline rhuTNF & $-4.5 \pm 2.1$ & $-4.9 \pm 2.7$ & $-6.4 \pm 2.7$ & $-6.0 \pm 2.4$ \\
\hline $\begin{array}{l}\text { rhuTNF + } \\
\text { L-NAME }\end{array}$ & $-4.7 \pm 3.1$ & $-7.1 \pm 2.1$ & $-7.1 \pm 2.4$ & $-7.5 \pm 4.2$ \\
\hline
\end{tabular}

Mean $\pm \mathrm{SD},(\mathrm{N})=$ number of animals studied. ${ }^{*} P<.05$ compared with control ${ }^{\ddagger} P<.05$ compared with rhuTNF; ${ }^{\S} P<.002$ compared with control; (all comparisons by Student's unpaired $t$ test)

Copenhagen). Mean arterial blood pressure (MBP) and intracranial pressure (ICP) were measured directly by water-filled pressure transducer (Statham P-23; Gould Inc., Santa Clara, CA), cerebral perfusion pressure (CPP) was calculated as the difference between MBP and ICP. Cerebral blood flow (CBF) was measured by the reference method using labeled $15-\mu \mathrm{m}$ plastic microspheres (9), after dissection of the brain into left and right hemispheres, brainstem and cerebellum. Cerebral metabolic rate for oxygen $\left(\mathrm{CMR}_{\mathrm{O} 2}\right)$ was calculated as the product of CBF times the arteriovenous difference for oxygen between blood samples taken from the femoral artery and the sagittal sinus; cerebrovascular resistance was calculated by dividing CPP by hemispheric $\mathrm{CBF}$, and oxygen extraction fraction was calculated by the equation $\mathrm{O}_{2}$ content arerial $_{\text {in }}$ - $\mathrm{O}_{2}$ content $_{\text {venous }} / \mathrm{O}_{2}$ content $\mathrm{t}_{\text {arterial }}$; lactate and glucose measurements were made in an autoanalyzer (YSI $2300 \mathrm{G} / \mathrm{L}$, Yellow Springs OH).

Study design. After animal preparation, baseline measurements of $\mathrm{CBF}, \mathrm{CMR}_{\mathrm{O} 2}$, and CSF lactate and glucose were made. Rabbits were randomly assigned to receive either recombinant human TNF- $\alpha$ [rhuTNF] (Genentech Corp., So. San Francisco, CA) in saline (10 $\mu \mathrm{g})$ or vehicle by direct intracisternal injection. A third group was given rhuTNF intracisternally $30 \mathrm{~min}$ after an infusion of $\mathrm{N}-\omega$-nitro-L-arginine methyl ester $\mathrm{HCl}$ (L-NAME; Sigma Chemical Co., St. Louis, MO; $3.125-12.5 \mathrm{mg} / \mathrm{kg}$ iv ). Doses in this range have been demonstrated to inhibit cerebrovascular effects of nitric oxide (10) in the rabbit, and tissue concentrations which would be achieved with this dose have been shown to inhibit $\sim 50 \%$ of neuronal NOS activity (11) and $80 \%$ of endothelial NOS activity (12). Measurements of CBF, and $\mathrm{CMR}_{\mathrm{O} 2}$ were repeated at 2, 4, and $6 \mathrm{~h}$ thereafter. CSF lactate was measured at $6 \mathrm{~h}$. Data were analyzed by paired $t$ test for sequential measurements within groups and by unpaired t-test for comparison between experimental groups. Data were considered significant when $P \leq .05$.

\section{Results}

Eight control, eight rhuTNF, and six rhuTNF + L-NAME (LNAME) rabbits were studied. Groups were comparable in terms of baseline parameters. During the study period, arterial blood gases demonstrated that both groups of animals given rhuTNF hyperventilated to a modest degree, more in L-NAME-treated rabbits (Table I). $2 \mathrm{~h}$ after intracisternal injection of rhuTNF,
Table II. Physiological Parameters after Intracisternal Injection of rhuTNF

\begin{tabular}{|c|c|c|c|c|}
\hline & $0 \mathrm{~h}$ & $2 \mathrm{~h}$ & $4 \mathrm{~h}$ & $6 \mathrm{~h}$ \\
\hline \multicolumn{5}{|l|}{ MBP (mm Hg) } \\
\hline Control (8) & $73.9 \pm 7.4$ & $72.5 \pm 8.0$ & $73.6 \pm 7.5$ & $81.4 \pm 8.3$ \\
\hline rhuTNF (8) & $80.5 \pm 13.4$ & $85.8 \pm 13.7^{*}$ & $82.1 \pm 13.4$ & $79.8 \pm 13.6$ \\
\hline $\begin{array}{l}\text { rhuTNF + } \\
\text { L-NAME (6) }\end{array}$ & $80.6 \pm 10.1$ & $80.7 \pm 4.9$ & $82.5 \pm 12.7$ & $76.3 \pm 13.9$ \\
\hline \multicolumn{5}{|l|}{ ICP (mm Hg) } \\
\hline Control & $0.4 \pm 0.7$ & $0.9 \pm 0.9$ & $0.6 \pm 0.9$ & $1.4 \pm 1.1$ \\
\hline rhuTNF & $1.0 \pm 1.4$ & $2.9 \pm 1.6^{+.8}$ & $1.9 \pm 1.7^{1}$ & $1.6 \pm 0.9^{\S}$ \\
\hline $\begin{array}{c}\text { rhuTNF + } \\
\text { L-NAME }\end{array}$ & $0.2 \pm 0.5$ & $0.1 \pm 0.4$ & $0.1 \pm 0.4$ & $0.0 \pm 0.0 * *$ \\
\hline \multicolumn{5}{|l|}{ CPP (mm Hg) } \\
\hline Control & $73.5 \pm 7.5$ & $71.6 \pm 7.5$ & $73.0 \pm 7.6$ & $80.0 \pm 8.3$ \\
\hline rhuTNF & $79.4 \pm 12.8$ & $82.9 \pm 13.3$ & $80.2 \pm 13.0$ & $78.2 \pm 13.3$ \\
\hline $\begin{array}{l}\text { rhuTNF + } \\
\text { L-NAME }\end{array}$ & $80.4 \pm 10.0$ & $80.5 \pm 5.2^{*}$ & $82.3 \pm 12.8$ & $76.3 \pm 13.9$ \\
\hline
\end{tabular}

Mean $\pm \mathrm{SD},(\mathrm{N})=$ number of animals studied. ${ }^{*} P<.05$ compared with control ${ }^{\ddagger} P<.01$ compared with control; ${ }^{8} P<.001$ compared with rhuTNF $+\mathrm{L}$ NAME; $" ~ P<.02$ compared with rhuTNF + L-NAME; ${ }^{* *} P<.005$ compared with control; (all comparisons by Student's unpaired $t$ test).

blood pressure and intracranial pressure increased in rhuTNF rabbits compared with controls and L-NAME-treated rabbits (Table II). CBF was reduced significantly in rhuTNF-treated rabbits $2 \mathrm{~h}$ post-injection compared to controls $(63.9 \pm 11.4 \mathrm{ml} /$ min per 100 gm vs. $84.6 \pm 20.3 P<.05$, unpaired $t$ test $)$ and remained significantly lower throughout the study period. CBF reduction was also seen throughout the study period in brainstem, but not cerebellum, until $6 \mathrm{~h}$ after intracisternal injection of rhuTNF. CBF was also reduced in L-NAME-treated rabbits and followed the same general pattern as rhuTNF rabbits not given the drug. (Table III). Cerebrovascular resistance (CVR)

Table III. Regional Cerebral Blood Flow after Intracisternal Injection of rhuTNF

\begin{tabular}{|c|c|c|c|c|}
\hline & $0 \mathrm{~h}$ & $2 \mathrm{~h}$ & $4 \mathrm{~h}$ & $6 \mathrm{~h}$ \\
\hline \multicolumn{5}{|l|}{$\begin{array}{l}\text { Hemisphere }(\mathrm{ml} / \\
\mathrm{min} / 100 \mathrm{gm})\end{array}$} \\
\hline Control (8) & $89.0 \pm 17.6$ & $84.6 \pm 20.3$ & $99.4 \pm 25.0$ & $93.3 \pm 9.4$ \\
\hline $\operatorname{rhTNF}(8)$ & $84.1 \pm 20.6$ & $63.9 \pm 11.4 *$ & $68.3 \pm 16.5^{\ddagger}$ & $68.4 \pm 14.3^{8}$ \\
\hline $\begin{array}{l}\text { rhuTNF + } \\
\text { L-NAME (6) }\end{array}$ & $87.9 \pm 20.7$ & $67.8 \pm 15.5$ & $59.0 \pm 10.1^{\S}$ & $56.9 \pm 5.5^{9}$ \\
\hline \multicolumn{5}{|l|}{$\begin{array}{l}\text { Brainstem }(\mathrm{ml} / \mathrm{min} / \\
100 \mathrm{gm})\end{array}$} \\
\hline Control & $90.0 \pm 16.3$ & $85.3 \pm 29.5$ & $94.0 \pm 29.2$ & $91.3 \pm 6.7$ \\
\hline rhuTNF & $84.5 \pm 20.8$ & $59.9 \pm 12.7^{*}$ & $65.6 \pm 18.6 *$ & $60.8 \pm 8.6^{4}$ \\
\hline $\begin{array}{c}\text { rhuTNF + } \\
\text { L-NAME }\end{array}$ & $88.6 \pm 12.5$ & $76.2 \pm 23.0$ & $63.0 \pm 19.1 *$ & $64.6 \pm 16.1 * *$ \\
\hline \multicolumn{5}{|l|}{$\begin{array}{l}\text { Cerebellum }(\mathrm{ml} / \\
\mathrm{min} / 100 \mathrm{gm})\end{array}$} \\
\hline Control & $87.0 \pm 20.2$ & $85.0 \pm 24.0$ & $95.3 \pm 30.7$ & $96.3 \pm 17.0$ \\
\hline rhuTNF & $85.3 \pm 17.1$ & $72.6 \pm 19.8$ & $85.5 \pm 25.2$ & $73.8 \pm 18.1 *$ \\
\hline $\begin{array}{l}\text { rhuTNF + } \\
\text { L-NAME }\end{array}$ & $96.5 \pm 14.1$ & $74.8 \pm 15.8$ & $68.3 \pm 19.3$ & $59.0 \pm 6.5^{9}$ \\
\hline
\end{tabular}

Mean $\pm \mathrm{SD},(\mathrm{N})=$ number of animals studied. $* P<.05$ compared with control; ${ }^{\dagger} P<.02$ compared with control; ${ }^{\S} P<.002$ compared with control; ${ }^{\top} P<.001$ compared with control; ${ }^{* *} P<.005$ compared with control; (all comparisons by Student's unpaired $t$ test). 
Table IV. Cerebrovascular Resistance

\begin{tabular}{lllll}
\hline & $0 \mathrm{~h}$ & $2 \mathrm{~h}$ & $4 \mathrm{~h}$ & $6 \mathrm{~h}$ \\
\hline $\begin{array}{c}\text { Resistance (mm Hg/ } \\
\mathrm{ml} / \mathrm{min} / 100 \mathrm{gm})\end{array}$ & & & & \\
Control (8) & $0.90 \pm 0.21$ & $0.92 \pm 0.26$ & $0.80 \pm 0.21$ & $0.85 \pm 0.05$ \\
rhuTNF (8) & $0.95 \pm 0.18$ & $1.29 \pm 0.14^{*}$ & $1.09 \pm 0.16^{*}$ & $1.16 \pm 0.40^{\ddagger}$ \\
rhuTNF + & $0.98 \pm 0.33$ & $1.28 \pm 0.46$ & $1.54 \pm 0.35^{\ddagger \S}$ & $1.33 \pm 0.31^{*}$ \\
L-NAME (6) & & & & \\
& & & & \\
\hline
\end{tabular}

Mean $\pm \mathrm{SD},(\mathrm{N})=$ number of animals studied. $* P<0.005$ compared with control; ${ }^{\ddagger} P<.001$ compared with control; ${ }^{\S} P<.02$ compared with rhuTNF; ${ }^{9} P<.05$ compared with control; (all comparisons by Student's unpaired $t$ test).

did not change in control rabbits during the study period. By contrast, CVR increased $35.8 \%$ in rhuTNF rabbits and $30.6 \%$ in L-NAME rabbits $2 \mathrm{~h}$ after intracisternal rhuTNF and remained elevated for the duration of the study (Table IV). Cerebral oxygen uptake decreased acutely in rhuTNF rabbits. Two hours after intracisternal injection, $\mathrm{CMRO}_{2}$ had decreased significantly in the rhuTNF rabbits compared to baseline $(3.58 \pm 0.33$ $\mathrm{ml} / \mathrm{min}$ per $100 \mathrm{gm}$ vs $5.20 \pm 1.15 ; P<.005$, paired $t$ test $)$ and was significantly lower than controls $(4.80 \pm 1.02 ; P<.005$, unpaired $t$ test). $\mathrm{CMR}_{\mathrm{O} 2}$ in L-NAME-treated rabbits did not decrease, and was comparable to control rabbits. $\mathrm{CMR}_{\mathrm{O} 2}$ returned toward baseline level in rhuTNF rabbits at 4 and $6 \mathrm{~h}$ and was unchanged in controls and L-NAME-treated rabbits throughout the study period ( Table $\mathrm{V}$ ). The reduction in $\mathrm{CMR}_{\mathrm{O} 2}$ at $2 \mathrm{~h}$ occurred as a consequence of both the reduction in $\mathrm{CBF}$ and reduction in oxygen extraction fraction (OEF), and at 4 and $6 \mathrm{~h}$ by reduction in CBF (Tables III and V). CSF lactate increased significantly in rhuTNF-treated rabbits compared both to controls and L-NAME rabbits at $6 \mathrm{~h}(3.2 \pm 0.6 \mathrm{mM} /$ liter vs $1.9 \pm 0.4$ [control] and $2.1 \pm 1.0$ [L-NAME]; $P<.001$ [control ], $P<.05$ [L-NAME].) (Table VI). In addition, there was a decrease in the CSF/blood glucose ratio in rhuTNF-treated rabbits $(0.90 \pm .08[0 \mathrm{~h}]$ vs $0.79 \pm .10[6 \mathrm{~h}] ; P=.03$, paired $t$ test), a finding not observed in controls or L-NAME-treated rabbits (Table VI).

Table V. Cerebral Oxygen Uptake (CMRO2) and Oxygen Extraction Fraction (OEF) after Intracisternal Injection of rhuTNF

\begin{tabular}{|c|c|c|c|c|}
\hline & $0 \mathrm{~h}$ & $2 \mathrm{~h}$ & $4 \mathrm{~h}$ & $6 \mathrm{~h}$ \\
\hline \multicolumn{5}{|l|}{$\begin{array}{c}\mathrm{CMR}_{\mathrm{O} 2}(\mathrm{ml} / \mathrm{min} / \\
100 \mathrm{gm})\end{array}$} \\
\hline Control (8) & $5.34 \pm 0.80$ & $4.80 \pm 1.02$ & $5.33 \pm 1.45$ & $4.78 \pm 0.34$ \\
\hline rhuTNF (7) & $5.20 \pm 1.15$ & $3.58 \pm 0.33^{*}$ & $4.55 \pm 0.70$ & $4.47 \pm 0.91$ \\
\hline $\begin{array}{l}\text { rhuTNF + } \\
\text { L-NAME (5) }\end{array}$ & $4.67 \pm 1.44$ & $5.25 \pm 1.94$ & $5.25 \pm 1.32$ & $4.49 \pm 0.57$ \\
\hline \multicolumn{5}{|l|}{ OEF } \\
\hline Control (8) & $0.34 \pm 0.09$ & $0.34 \pm 0.06$ & $0.35 \pm 0.08$ & $0.37 \pm 0.09$ \\
\hline rhuTNF (7) & $0.29 \pm 0.08$ & $0.27 \pm 0.05^{\ddagger}$ & $0.33 \pm 0.07$ & $0.34 \pm 0.08$ \\
\hline $\begin{array}{l}\text { rhuTNF + } \\
\text { L-NAME (5) }\end{array}$ & $0.28 \pm 0.03$ & $0.42 \pm 0.07^{\ddagger \S}$ & $0.55 \pm 0.11^{1 * *}$ & $0.46 \pm 0.08^{\ddagger \ddagger}$ \\
\hline
\end{tabular}

Mean $\pm \mathrm{SD},(\mathrm{N})=$ number of animals studied. $* P<.005$ compared with control; ${ }^{\ddagger} P<.05$ compared with control; ${ }^{8} P<.001$ compared with rhuTNF; ${ }^{\circledR} P<.002$ compared with rhuTNF; ${ }^{* *} P<.005$ compared with control; ${ }^{\ddagger \ddagger} P<.02$ compared with rhuTNF; (all comparisons by Student's unpaired $t$ test).
Table VI. CSF Parameters after Intracisternal Injection of rhuTNF

\begin{tabular}{lcc}
\hline & $0 \mathrm{~h}$ & $6 \mathrm{~h}$ \\
\hline CSF Lactate (mM/liter) & & \\
Control (8) & $1.4 \pm 0.6$ & $1.9 \pm 0.4$ \\
rhuTNF (8) & $1.6 \pm 0.6$ & $3.2 \pm 0.6^{* \ddagger}$ \\
rhuTNF + L-NAME (6) & $1.6 \pm 0.7$ & $2.1 \pm 1.0$ \\
CSF/blood glucose ratio & & \\
Control (8) & $0.89 \pm .14$ & $0.88 \pm 0.10$ \\
rhuTNF (8) & $0.90 \pm .08$ & $0.79 \pm 0.10^{\S}$ \\
rhuTNF + L-NAME (6) & $0.84 \pm 0.11$ & $0.83 \pm .014$ \\
\hline
\end{tabular}

Mean $\pm \mathrm{SD},(\mathrm{N})=$ number of animals studied. $* P<.001$ compared with control; ${ }^{\ddagger} P<.05$ compared with rhuTNF + L-NAME; ${ }^{\S} P<$ .05 compared with baseline rhuTNF (paired $t$ test); (comparisons by Student's unpaired $t$ test except as noted).

\section{Discussion}

Pro-inflammatory cytokines (TNF-alpha, IL-1 $\beta$, IL-6) have been shown to be present in high concentrations in CSF in bacterial meningitis (13-15), have been associated with poor neurologic outcome (14), and have been implicated as mediators of inflammatory changes and blood-brain barrier injury in the central nervous system in this disease $(16,17)$. They appear to be locally produced by the brain in response to components of the bacterial cell wall, and are thought to cause the influx of granulocytes from cerebral capillaries to the subarachnoid space by upregulation of leukocyte selections on cerebral capillary endothelium (18). An indication that cytokines may be mediators of circulatory and metabolic abnormalities in bacterial meningitis can be inferred from the findings of Mustafa et al., who reported that elevated concentrations of TNF and IL- $1 \beta$ were correlated with CSF lactate concentration as well as poor neurologic outcome (14).

In peripheral tissues, cytokines are thought to induce many of the circulatory and metabolic effects of endotoxemia, including hypotension, reduced oxygen consumption and increased glucose uptake and lactate production (19). Tracey et al. demonstrated that intravenous TNF induced circulatory and metabolic abnormalities similar to that seen in endotoxic shock (20), and later demonstrated that pretreatment with anti-TNF monoclonal antibodies blocked these effects in studies of experimental bacteremia (21). While these effects have been reported in a number of peripheral tissues, including muscle, liver, spleen, skin, kidney, and heart, they have specifically not been reported to occur in brain (22).

More recently, it has been recognized that many of the circulatory and metabolic effects of cytokines are due to induction of nitric oxide synthase (NOS) and subsequent generation of nitric oxide (NO) $(23,24)$. In vivo evidence for this was provided by Kilbourn et al. who demonstrated that intravenous TNF- $\alpha$-induced hypotension in dogs was completely reversed by treatment with $\mathrm{N}$-G-methyl-L-arginine, an inhibitor of NOS (25). In vitro studies of the effect of nitric oxide on isolated mitochondria have demonstrated inhibition of mitochondrial respiration from a number of tissues, including skeletal muscle (26), tumor cells (27), vascular smooth muscle cells (28), and 
hepatocytes (29). The effects on mitochondrial metabolism are thought to occur by inhibition of the Krebs cycle enzyme, aconitase $(29,30)$ and complexes I and II of the mitochondrial respiratory chain $(28,29)$. It has been recently suggested that another reactive nitrogen species, peroxynitrite, formed by the reaction between nitric oxide and superoxide anion (31) may have similar effects on mitochondrial respiration.

As in peripheral tissues in models of sepsis, decreased oxygen consumption and anaerobic metabolism occurs in the CNS in meningitis. Paulson et al. found decreased $\mathrm{CMR}_{\mathrm{O} 2}$ in patients with meningitis due to Streptococcus pneumoniae (32), and we have reported similar findings in experimental meningitis in the rabbit. In addition, in that study we observed a significant correlation between CSF TNF concentration and $\mathrm{CMR}_{\mathrm{O} 2}$, and TNF concentration and CSF lactate (33). We hypothesize that these findings may be explained by either a direct effect of TNF on cells in the CNS or by TNF-induced NO synthesis. In the present study, intracisternal injection of rhuTNF led to a significant reduction in oxygen uptake, an increase in CSF lactate and reduction in the CSF/blood glucose ratio, which were blocked by inhibition of NOS. Although the changes in oxygen uptake and CSF lactate were modest in rhuTNF-treated rabbits, we believe they provide important in vivo confirmation of in vitro studies delineating the role of $\mathrm{NO}$ in cellular oxidative metabolism. The significance of the reduction in CSF/blood glucose ratio, also blocked by L-NAME, is less clear. It is known that glucose transport across the blood-brain barrier is impaired in meningitis (34), and hypoglycorrhachia has been shown to correlate with CSF TNF concentration (14). In this study, although there was a significant reduction in the CSF/ blood glucose ratio in rhuTNF-treated rabbits compared to baseline, there was only a trend toward lower levels when directly compared to controls $(P<.10)$, and while the reduction was not seen in rhuTNF rabbits given L-NAME, the mechanism by which NO inhibition would prevent this reduction is not clear. Zeller has recently reported that TNF downregulates GLUT 2mRNA in the rat pancreas (35), and while this has not been demonstrated for brain it is possible that a similar mechanism may exist, by which TNF may limit glucose transport in the CNS. In the only previously published study which examined the effect of TNF on cerebral cellular metabolism in vivo, Meszaros et al., using 2-deoxyglucose, failed to find increased cerebral glucose uptake in brain, while demonstrating increased uptake in other tissues after intravenous administration of TNF (22). It is not surprising that they would fail to demonstrate an effect in brain, as TNF would not be expected to cross the intact blood-brain barrier following intravenous infusion, and therefore would not have access to neurons or other cells of the CNS.

This study also provides evidence that TNF or NO may play a role in increased intracranial pressure, possibly by an effect on vascular tone in cerebral capacitance vessels. We have previously shown that increased intracranial pressure is associated with increased cerebral blood flow in experimental pneumococcal meningitis ( 8 ) and this has also been shown by Pfister et al. (36). Furthermore, Haberl et al. have recently demonstrated that treatment with an NOS inhibitor blocks the increase in ICP associated with increased CBF in the early phase of pneumococcal meningitis (37) in the rat. The present study also demonstrates complete blockade of increased ICP with NOS inhibition; however, this finding differs from our previous ob- servation and the finding by Haberl in that the increase in ICP in rhuTNF-treated rabbits occurred at a time when cerebral blood flow was reduced, indicating a different mechanism of increased ICP mediated by NO. Increased ICP can result from an increase in any intracranial component, including brain (i.e., brain edema), CSF and intracranial blood. L-NAME treatment has been shown in experimental meningitis to prevent brain edema (37); however, the pattern we observed, with maximal ICP increase at two hours suggests that brain edema is unlikely to be the cause. Brain edema in experimental models such as this would not be expected to be transient and of such short duration. Pfister et al. have demonstrated progressive pathophysiologic abnormalities after intracisternal injection of pneumococci, with significant increase in brain edema measured at $6 \mathrm{~h} \mathrm{(36).} \mathrm{Alternatively,} \mathrm{it} \mathrm{is} \mathrm{possible} \mathrm{that} \mathrm{the} \mathrm{increase} \mathrm{in} \mathrm{ICP}$ occurred because of increased CSF volume, either through increased CSF production or decreased resorption secondary to increased outflow resistance. Faraci and Heistad have shown that NO may be involved in regulating blood flow to the choroid plexus (CP), the major site of CSF production (38), and a preliminary study by that group has shown that intraventricular injection of TNF increases choroid plexus flow and that the increase is blocked by NO inhibition (10). It is known that decreased CP flow is associated with decreased CSF production, therefore it is possible that increased CP flow might lead to increased CSF production. However, it is generally accepted that CSF formation does not increase with increased CP blood flow (CPBF), based on studies where CSF formation was not increased after CPBF was increased by hypercapnia, atriopeptin, and vasoactive intestinal peptide (39-41). CSF outflow resistance is increased in experimental bacterial meningitis in the rabbit (42); however, this is thought to be due to direct injury to the arachnoid granulations, and like brain edema, would not be transient. In this study, the inhibition of ICP elevation by NO inhibition suggests a vascular mechanism. It is possible that the increase in ICP in rhuTNF-treated rabbits occurred because of NO-induced reduction in vascular tone in the intracranial capacitance vessels, leading to increased intracerebral blood volume. Increased intracerebral blood volume has been shown to contribute to intracranial hypertension in other forms of brain injury (43).

Whereas the changes in oxygen uptake, CSF lactic acidosis and increased ICP were attenuated by inhibition of NO, changes in $\mathrm{CBF}$ were not. CBF was reduced by $2 \mathrm{~h}$ and remained low throughout the study period following intracisternal injection of rhuTNF. This is consistent with the finding of Megyeri et al. who previously showed a dose-dependent reduction in pial artery diameter following intracisternal injection of rhuTNF in the rat (44); however, in that study, cortical blood flow was not measured. The mechanism by which blood flow was reduced in this study appears to have at least two components. First, there was a generalized increase in CVR which persisted throughout the study. In the acute phase, there was also a symmetric depression of oxygen uptake and $\mathrm{CBF}$, suggesting that at that time $\mathrm{CBF}$ was reduced secondary both to reduced oxygen demand and increased CVR. At 4 and $6 \mathrm{~h}$; however, oxygen uptake was lower but not significantly different from controls. At those times, increased CVR appears to be the mechanism of reduced flow. The present study did not address the mechanism of increased cerebrovascular resistance. Increased CVR was probably due in part, to decreased $\mathrm{P}_{\mathrm{a}} \mathrm{CO}_{2}$ in animals given 
rhuTNF; however, the changes in CVR and CBF observed are greater than would have been predicted from the reduction in $\mathrm{P}_{\mathrm{a}} \mathrm{CO}_{2}$, which are $\sim 2 \%$ per 1.0 torr change in $\mathrm{P}_{\mathrm{a}} \mathrm{CO}_{2}$ (45). It is also possible that rhuTNF induced not only NO, but compounds with vasoconstrictor properties as well. TNF has been reported to release endothelin-1, a potent vasoconstrictor, from bovine aortic, renal artery and glomerular capillary endothelial cells (46) and has been shown to increase plasma ET-1 and ET-3 after intravenous infusion in the rat (47). The symmetric reduction in CBF to all regions studied suggests either a uniform effect on cellular demand or a direct effect on cerebral vasculature.

In summary, after intracisternal injection of rhuTNF in the rabbit, we found a number of cerebrovascular, physiologic and cerebrometabolic changes which occur in patients with bacterial meningitis. These include reduction in cerebral oxygen uptake and cerebral blood flow, increased intracranial pressure, decreased CSF/blood glucose ratio and evidence for increased anaerobic metabolism associated with cerebrospinal fluid lactic acidosis. Reduction in cerebral oxygen uptake, intracranial hypertension, reduced blood-brain transport of glucose and CSF lactic acidosis were blocked by inhibition of nitric oxide synthase, indicating that TNF-induced nitric oxide plays a major role in these abnormalities. Reduction in cerebral blood flow appeared to be independent of nitric oxide and was primarily due to increased cerebrovascular resistance, with an early contribution from decreased cellular demand. In addition to the welldescribed pro-inflammatory effects of TNF in the CNS, this study suggests that TNF-induced release of nitric oxide is an additional mechanism for the pathogenesis of brain injury by cytokines in meningitis and other CNS conditions where cytokines are locally produced.

\section{Acknowledgments}

The author thanks Merle A. Sande, M.D. for his critical review of this manuscript.

This work was supported in part by PHS Grants NS 27310 and NS 32553. Technical assistance was provided by Jeff Froula, Qingxiang Liu, Berkley R. Elliott, Jr., and Marinka Kartalija.

\section{References}

1. Mustafa, M. M., O. Ramilo, K. D. Olsen, P. S. Franklin, E. J. Hansen, B. Beutler, and G. H. McCracken, Jr. 1989. Tumor necrosis factor a in mediating experimental Haemophilus influenzae type b meningitis. J. Clin. Invest. 84:12531259.

2. Brook, I., K. S. Bricknell, G. D. Overturf, and S. M. Feingold. 1978. Measurement of lactic acid in cerebrospinal fluid of patients with infections of the central nervous system. J. Infect. Dis. 137:384-390.

3. Nishimura, K. 1924. The lactic acid content of blood and spinal fluid. Proc. Soc. Exp. Biol. Med. 22:323-324.

4. Killian, J. 1925. Lactic acid of normal and pathological spinal fluids. Proc. Soc. Exp. Biol. Med. 23:255-257.

5. Petersdorf, R., D. Swarner, and M. Garcia. 1963. Studies on the pathogenesis of meningitis. relationship of phagocytosis to the fall in cerebrospinal fluid sugar in experimental pneumoccocal meningitis. J. Lab. Clin. Med. 61:745-754.

6. Guerra-Romero, L., M. G. Täuber, M. A. Fournier, and J. H. Tureen. 1992. Lactate and glucose concentrations in brain interstitial fluid, cerebrospinal fluid and serum during experimental pneumococcal meningitis. J. Infect. Dis. 166:546550.

7. Tureen, J. H., M. G. Täuber, and M. A. Sande. 1992. Effect of hydration status on cerebral blood flow and cerebrospinal fluid lactic acidosis in rabbits with experimental meningitis. J. Clin. Invest. 89:947-953.

8. Tureen, J. H., R. J. Dworkin, S. L. Kennedy, M. Sachdeva, and M. A.
Sande. 1990. Loss of cerebrovascular autoregulation in experimental meningitis in rabbits. J. Clin. Invest. 85:577-581.

9. Heymann, M. A., B. D. Payne, J. I. E. Hoffman, and A. M. Rudolph. 1977. Blood flow measurements with radionuclide-labeled particles. Prog. Cardiovasc. Dis. 20:55-70.

10. Kinzenbaw, D. A., D. D. Heistad, and F. M. Faraci. 1994. Tumor necrosis factor produces nitric oxide-mediated increases in blood flow to choroid plexus. FASEB (Fed. Am. Soc. Exp. Biol.) J. 8:A27 (Abstract).

11. Iadecola, C., X. Xu, F. Zhang, J. Hu, and E. E. el-Fakahany. 1994. Prolonged inhibition of brain nitric oxide synthase by short-term systemic administration of nitro-L-arginine methyl ester. Neurochem. Res. 19:501-505.

12. Rees, D. D., R. M. J. Palmer, R. Schulz, H. F. Hodson, and S. Moncada. 1990. Characterization of three inhibitors of endothelial nitric oxide synthase in vitro and in vivo. Br. J. Pharmacol. 101:746-752.

13. Mustafa, M. M., O. Ramilo, X. Saez-Llorens, J. Mertsola, R. R. Magness, and G. H. McCracken, Jr. 1989. Prostaglandin E2 and I2, interleukin-1 $\beta$, and tumor necrosis factor in cerebrospinal fluid of infants and children with bacterial meningitis. Pediatr. Infect. Dis. J. 8:921-922.

14. Mustafa, M. M., M. H. Lebel, O. Ramilo, K. O. Olsen, J. S. Reisch, B. Beutler, and G. H. McCracken, Jr. 1989. Correlation of interleukin-1 $\beta$ and cachectin concentrations in cerebrospinal fluid and outcome from bacterial meningitis. J. Pediatr. 115:208-213.

15. Waage, A., A. Halstensen, R. Shalaby, P. Brandtz, P. Kierule, and T. Espevik. 1989. Local Production of tumor necrosis factor a. interleukin 1, and interleukin 6 in meningococcal meningitis. J. Exp. Med. 170:1859-1867.

16. Quagliarello, V. J., B. Wispelwey, W. J. Long, and W. M. Scheld. 1991. Recombinant human interleukin-1 induces meningitis and blood-brain barrier injury in the rat. J. Clin. Invest. 87:1360-1366.

17. Saukkonen, K., S. Sande, C. Cioffe, S. Wolpe, B. Sherry, A. Cerami, and E. Tuomanen. 1990. The role of cytokines in the generation of inflammation and tissue damage in experimental gram-positive meningitis. J. Exp. Med. 171:439448 .

18. Quagliarello, V. J., and W. M. Scheld. 1992. Bacterial meningitis: pathogenesis, pathophysiology, and progress. N. Engl. J. Med. 327:864-872.

19. Natanson, C., P. Eichenholz, and R. Danner. 1989. Endotoxin and tumor necrosis factor challenges in dogs simulate the cardiovascular profile of human septic shock. J. Exp. Med. 169:823-32.

20. Tracey, K. J., B. Beutler, S. F. Lowry, J. Merryweather, S. Wolpe, I. W. Milsark, R. J. Hariri, T. J. I. Fahey, A. Zentella, J. D. Albert, G. T. Shires, and A. Cerami. 1986. Shock and tissue injury induced by recombinant cachectin. Science (Wash. DC). 234:470-474.

21. Tracey, K., Y. Fong, D. G. Hesse, K. R. Manogue, A. T. Lee, G. C. Kuo, S. F. Lowry, and A. Cerami. 1987. Anti-cachectin/TNF monoclonal antibodies prevent septic shock during lethal bacteremia. Nature (Lond.). 330:662-664.

22. Meszaros, K., C. H. Lang, G. J. Bagby, and J. J. Spitzer. 1987. Tumor necrosis factor increases in vivo glucose utilization of macrophage-rich tissue. Biochem. Biophys. Res. Commun. 149:1-6.

23. Busse, R., and A. Mulsch. 1990. Induction of nitric oxide synthase by cytokines in vascular smooth muscle cells. FEBS (Fed. Eur. Biochem. Soc.) Lett. 275:87-90.

24. Nussler, A. K., M. Di Silvio, T. R. Billiar, R. A. Hoffman, and D. A. Geller 1992. Stimulation of the nitric oxide synthase pathway in human hepatocytes by cytokines and endotoxin. J. Exp. Med. 176:261-264.

25. Kilbourn, R. G., S. S. Gross, A. Jubran, J. Adams, O. W. Griffith, R. Levi, and R. F. Lodato. 1990. NG-methyl-L-arginine inhibits tumor necrosis factor-induced hypotension: implications for the involvement of nitric oxide. Proc. Natl. Acad. Sci. USA. 87:3629-3632.

26. Cleeter, M. W., J. M. Cooper, V. M. Darley-Usmar, S. Moncada, and A. H. Schapira. 1994. Reversible inhibition of cytochrome c oxidase, the terminal enzyme of the mitochondrial respiratory chain, by nitric oxide. Implications for neurodegenerative diseases. FEBS (Fed. Eur. Biochem. Soc.) Lett. 345:50-54.

27. Tucker, S. D., E. J. Auzenne, and M. R. Sivaramakrishnan. 1993. Inhibition of tumor cell mitochondrial respiration by macrophage cytotoxic mediators distinct from interferon-gamma. J. Leukocyte Biol. 53:138-143.

28. Geng, Y., G. K. Hansson, and E. Holme. 1992. Interferon-gamma and tumor necrosis factor synergize to induce nitric oxide production and inhibit mitochondrial respiration in vascular smooth muscle cells. Circ. Res. 71:12681276.

29. Stadler, J., T. R. Billiar, R. D. Curran, D. J. Stuehr, J. B. Ochoa, and R. L. Simmons. 1991. Effect of exogenous and endogenous nitric oxide on mitochondrial respiration of rat hepatocytes. Am. J. Physiol. 260 (5 Pt 1):C910-916.

30. Welsh, N., S. Sandler. 1992. Interleukin-1-beta induces nitric oxide production and inhibits the activity of aconitase without decreasing glucose oxidation rates in isolated mouse pancreatic islets. Biochem. Biophys. Res. Comm. 182:333340 .

31. Radi, R., M. Rodriguez, L. Castro, and R. Telleri. 1994. Inhibition of mitochondrial electron transport by peroxynitrite. Arch. Biochem. Biophys. 308:89-95. 
32. Paulson, O. B., P. Brodersen, E. L. Hansen, and H. S. Kristensen. 1974. Regional cerebral blood flow, cerebral metabolic rate of oxygen, and cerebrospinal fluid acid-base variables in patients with acute meningitis and with acute encephalitis. Acta. Med. Scand. 196:191-198.

33. Tureen, J., Y. Kim, and J. Froula. 1993. TNF-alpha may mediate changes in cerebral blood flow and metabolism in experimental meningitis in rabbits. Ped. Res. 33:186A.

34. Brooke-Williams, R. 1964. Alterations in the glucose transport mechanism in patients with complications of bacterial meningitis. Pediatrics. 34:491-502.

35. Zeller, W., M. Goto, J. Parker, J. Cava, C. Hofmann, M. Gottschalk, C. Anderson. 1994. TNF-alpha alters islets of Langerhans insulin release and GLUT2 mRNA abundance in 10 day old rats. Ped. Res. 34:209A.

36. Pfister, H. W., U. Koedel, R. L. Haberl, U. Dirnagl, W. Feiden, L. G. Kuckdesche, and K. M. Einhaupl. 1990. Microvascular changes during the early phase of experimental bacterial meningitis. J. Cereb. Blood Flow Metab. 10:914922.

37. Haberl, R. L., F. Anneser, U. Kodel, and H. W. Pfister. 1994. Is nitric oxide involved as a mediator of cerebrovascular changes in the early phase of experimental pneumococcal meningitis? Neurosci. Res. 16:108-112.

38. Faraci, F. M., and D. D. Heistad. 1992. Does basal production of nitric oxide contribute to regulation of brain-fluid balance? Am. J. Physiol. 262 (2 Pt 2):H340-344.

39. Hochwald, G. M., C. Malhan, and J. Brown. 1973. Effect of hypercapnia on CSF turnover and blood-CSF barrier to protein. Arch. Neurol. 28:150-156.
40. Nilsson, C., M. Lindvall-Axelsson, and C. Owman. 1991. Simultaneous and continuous measurement of choroid plexus blood flow and cerebrospinal fluid production: effects of vasoactive intestinal polypeptide. J. Cereb. Blood Flow Metab. 11:861-867.

41. Schalk, K. A., F. M. Faraci, J. L. Williams, D. VanOrden, and D. D. Heistad. 1992. Effect of atriopeptin on production of cerebrospinal fluid. J. Cereb. Blood Flow Metab. 12:691-696.

42. Scheld, W. M., R. G. Dacey, H. R. Winn, J. E. Welsh, J. A. Jane, and M. A Sande. 1980. Cerebrospinal fluid outflow resistance in rabbits with experimenta meningitis. J. Clin. Invest. 66:243-253.

43. Hirai, O., H. Handa, and M. Ishikawa. 1986. Cerebral blood volume as another cause of intracranial hypertension following cold-induced edema. In Intracranial Pressure VI. J. D. Miller et al., editors. Springer-Verlag, Berlin.

44. Megyeri, P., C. Abraham, P. Temesvari, J. Kovacs, T. Vas, C. Speer. 1992. Recombinant human tumor necrosis factor alpha constricts pial arterioles and increases blood-brain barrier permeability in newborn piglets. Neurosci. Lett. 148:137-140.

45. Grubb, R. L., M. E. Raichle, J. O. Eichling, and M. M. Ter-Pogossian 1974. The effects of changes in $\mathrm{PaCO} 2$ on cerebral blood volume, blood flow, and vascular mean transit time. Stroke. 5:630-639.

46. Marsden, P. A., and B. M. Brenner. 1992. Transcriptional regulation of the endothelin-1 gene by TNF-alpha. Am. J. Physiol. 262 (4 Pt 1):C854-861.

47. Vemulapalli, S., P. J. Chiu, M. Rivelli, C. J. Foster, E. J. Sybertz. 1991 Modulation of circulating endothelin levels in hypertension and endotoxemia in rats. J. Cardiovasc. Physiol. 18:895-903. 